\title{
Percepción del desempeño de la actividad turística rumbo a la sostenibilidad en Loreto, Baja California Sur, México
}

\author{
Elizabeth Olmos-Martínez* Juan Pedro Ibarra-Michel** \\ Mónica Velarde-Valdez*** \\ Universidad Autónoma de Occidente (México)
}

\begin{abstract}
Resumen: Loreto es un destino turístico que cuenta con características sobresalientes para la práctica del turismo cultural y de naturaleza, tiene el distintivo como Pueblo Mágico otorgado por la Secretaría de Turismo de México; además, es parte del área de influencia del Parque Nacional Bahía de Loreto. A partir de lo anterior, el presente trabajo se centra en la caracterización y desempeño de la actividad turística considerando la percepción del turista y actores clave del lugar. Se utilizó una metodología de tipo cualitativa con enfoque descriptivo, utilizando entrevistas, encuestas y guías de observación. Los resultados muestran una percepción positiva y una satisfacción sobresaliente del turista acerca de la calidad, el cuidado y conservación de los atractivos culturales y naturales del destino, no obstante, los actores clave perciben prácticas no sostenibles y falta de consenso en la toma de decisiones. A la vez, se aprecia una actividad creciente de iniciativas privadas y gubernamentales que pueden favorecer las prácticas del turismo sostenible.
\end{abstract}

Palabras Clave: Turismo; Percepción; Loreto; Baja California Sur; México.

Perception of the performance of tourism activity towards sustainability in Loreto, Baja California Sur, Mexico

Abstract: Loreto is a tourist destination that has outstanding characteristics for the practice of cultural and nature tourism, it has a distinctive as a Magical Town granted by the Tourism Secretary of Mexico; It is also part of the area of influence of Loreto Bay National Park. Based on the foregoing, the present work focuses on the characterization and performance of the tourist activity considering the perception of the tourist and key actors of the place. A qualitative methodology with a descriptive approach was used, using interviews, surveys and observation guides. The results show a positive perception and an outstanding satisfaction of the tourist about the quality, care and conservation of the cultural and natural attractions of the destination; however, the key actors perceive unsustainable practices and lack of consensus in decision making. At the same time, there is an increasing activity of private and governmental initiatives that can favor sustainable tourism practices.

Keywords: Tourism; Perception; Loreto; Baja California Sur, Mexico.

\section{Introducción}

De acuerdo con Ibarra y Velarde (2016) el turismo sostenible (TS) debe tener en cuenta una participación social amplia para democratizar las decisiones y asumir las responsabilidades que implica la conservación del patrimonio territorial y paisajístico de una localidad o región. En ese sentido, el territorio y sus recursos sociales, culturales y ambientales ahora son considerados recursos susceptibles de generar economía local con base en el entramado de los diversos productores y empresarios propietarios de la economía de los servicios y la dinámica de las familias del ámbito rural, todo ello en conjunto como

\footnotetext{
* Universidad Autónoma de Occidente (México); E-mail: eolmosm.udo@gmail.com; http://orcid.org/0000-0002-7408-0811

** Universidad Autónoma de Occidente (México); E-mail: juanpedroibarra.udo@gmail.com; http://orcid.org/0000-0002-7729-6474

*** Universidad Autónoma de Occidente (México); E-mail: mvelardemx@yahoo.com; http://orcid.org/0000-0002-1937-8690
} 
generadora de bienestar (Hoyos y Hernández, 2008). Ante lo dicho, las localidades urbano-rurales con perfil turístico se sustentan en la explotación de recursos tradicionales (histórico-culturales) y valor ambiental (Ibáñez y Olmos-Martínez, 2015).

El presente trabajo muestra la percepción del turista y de los actores clave acerca del desempeño de la actividad turística en Loreto, Baja California Sur (BCS), México, lugar que se encuentra en un contexto de distinción y protección gubernamental doble, por un lado la parte marina cuenta con un decreto, desde 1996, como Área Natural Protegida (ANP) designada por el gobierno federal en la categoría de Parque Nacional, se trata de un sitio con representatividad biogeográfica de uno o más ecosistemas con belleza escénica, valor científico, educativo, de recreo, valor histórico, existencia de flora y fauna, aptitud para el turismo (DOF, 2018). El Parque presenta una gran variedad de ambientes costeros marinos con fondos rocosos, arenosos, playas, cañadas, cañones submarinos y terrazas marinas. Esto, aunado a su ubicación geográfica ha favorecido el establecimiento de una variedad de hábitats con una elevada diversidad biológica (SEMARNAP-CONANP, 2000). Por otro lado, tiene la distinción de Pueblo Mágico por parte de la Secretaría de Turismo (SECTUR) ya que cuenta con atractivos naturales, históricos y culturales que lo hacen un sitio singular. El Programa de Pueblos Mágicos al que pertenece Loreto busca estructurar una oferta turística con atributos histórico-culturales, generación de productos turísticos basados en las expresiones de la cultura local y consolidar y reforzar los atractivos con potencial turístico que generen flujos de turistas para el beneficio de la comunidad receptora, todo ello bajo el esquema de sostenibilidad. Dado lo anterior, la doble designación de protección y distinción hace que Loreto sea un sitio ideal para la práctica del TS.

No obstante, las características antes mencionadas de Loreto se percibe el problema de bajo nivel de colaboración entre el gobierno estatal y municipal, el comité del Pueblo Mágico y los operadores turísticos, llámese hoteleros y restauranteros en mayor medida. Lo anterior implica que los esfuerzos aislados no logren objetivos trascendentes para la sostenibilidad y estos se den a mayor plazo. Asimismo, se observa falta de información actualizada que provenga de los principales usuarios de los servicios turísticos y que ofrezca la caracterización y desempeño de la actividad turística en Loreto, ya que de acuerdo con los actores clave, la planeación para el desarrollo del turismo que realiza el gobierno se basa en decisiones municipales (a partir de indicadores generales) más que locales, ignorando de cierto modo la singularidad del lugar y los datos locales que indican la realidad de un espacio determinado. Lo que conlleva a una planeación con pocas posibilidades de éxito y que la meta de un destino sostenible se complique.

De acuerdo con Salinas y La O (2006) desde el paradigma de la sostenibilidad es necesario promover enfoques alternativos para el desarrollo, que permitan lograr dicha sostenibilidad de manera ordenada, entre ellos se encuentran el uso de indicadores para evaluar la sostenibilidad del turismo en los destinos; el establecimiento de lineamientos para el desarrollo de áreas de TS de forma regional, transfronterizas, etc.; la realización de las Agendas Locales 21 y los Planes de Desarrollo Territorial Sustentable en los destinos turísticos y; por último, realizar estudios de la actividad turística, a escala local, buscando la planificación del turismo desde los espacios receptores, y adecuando la actividad a las condiciones específicas de cada territorio y sus características económicas y sociales. En ese sentido, la presente investigación se centra en caracterizar el desempeño de la actividad turística a partir de un estudio local con la finalidad de coadyuvar en la planificación con las condiciones específicas de Loreto y sus características económicas y sociales.

En el proceso del TS los estudios de la actividad turística a escala local permiten conocer las tendencias, el cumplimiento de los objetivos anteriormente planteados, brindan posibilidades de intervención oportuna permitiendo la toma de decisiones adecuadas y bien fundamentadas en el propio proceso de planificación y gestión de cada destino en particular, convirtiéndose también en mecanismos de enseñanza y estímulo para alcanzar la sostenibilidad.

Derivado de lo anterior, el objetivo general de esta investigación es caracterizar el desempeño de la actividad turística considerando la percepción del turista y actores clave, a partir de sus atributos sociales, culturales y ambientales rumbo a la sostenibilidad. Se pretende identificar una serie de puntos clave que por el momento se manifiestan como problemas, pero con la voluntad gubernamental y trabajo conjunto pueden ser atendidas en corto y mediano plazo. En resumen, se busca que los tomadores de decisiones tengan información local y actualizada, que puedan incorporar en la planeación para el desarrollo del TS (ambiental, cultural-religioso) y por ende coadyuve en el desarrollo socioeconómico de Loreto. Se utilizó una metodología de tipo cualitativa, con enfoque descriptivo ya que presenta rasgos, cualidades y atributos de la población objeto de estudio. Se apoyó de una revisión bibliográfica como herramienta para describir el contexto socioeconómico y ambiental de Loreto. Los resultados describen cualidades y atributos desde el punto de vista del turista y de actores clave. Se concluye con una serie de consideraciones finales. 


\section{Turismo sostenible}

El turismo es una actividad socioeconómica que involucra a muchos actores y niveles de gobierno, asimismo involucra diversos intereses de la sociedad. Dado que muchos de los atractivos turísticos están estrechamente relacionados con la riqueza natural de los destinos turísticos, la protección del medio ambiente es parte esencial de su propio desarrollo. Se asume que sin una adecuada calidad ambiental la actividad turística actual y su desarrollo futuro pueden verse comprometidos, al igual que las organizaciones turísticas, los turistas y las comunidades receptoras (Cater, 1995, citado en Salinas et al., 2008). Por otro lado, si no se planifica y gestiona de forma racional puede llevar a la degradación del medio ambiente y la pérdida de la identidad local (OMT, 2005).

En ese sentido, el TS se define por primera vez en 1991 en el marco del 41 Congreso de la Asociación Internacional de Expertos Científicos del Turismo (AIEST por sus siglas en francés), determinándolo de la siguiente manera "un turismo que mantiene un equilibrio entre los intereses sociales, económicos y ecológicos, integrando las actividades económicas y recreativas con el objeto de buscar la conservación de los valores naturales y culturales" (AIEST, citado en Cardoso, 2006:8).

Por su parte, la Organización Mundial de Turismo (OMT, 2006), define al TS como "el turismo que tiene plenamente en cuenta las repercusiones actuales y futuras, económicas, sociales y medioambientales para satisfacer las necesidades de los visitantes, de la industria, del entorno y de las comunidades anfitrionas". Los principios de sostenibilidad se refieren a los aspectos medioambiental, económico y sociocultural del desarrollo turístico, habiéndose de establecer un equilibrio adecuado entre esas tres dimensiones para garantizar su sostenibilidad a largo plazo. Por tanto, el TS debe hacer un uso óptimo a los recursos medioambientales, respetar la autenticidad sociocultural de las comunidades anfitrionas y asegurar actividades económicas viables a largo plazo. Uno de los elementos fundamentales que destaca la OMT es que el desarrollo sostenible del turismo exige la participación informada de todos los agentes relevantes, así como un liderazgo político firme para lograr una colaboración amplia y establecer un consenso. El logro de un TS es un proceso continuo y requiere un seguimiento constante de sus incidencias, para introducir las medidas preventivas o correctivas que resulten necesarias.

Ahora bien, dado que el turismo ha tenido un crecimiento exponencial en los últimos años; desde los años 70 del siglo pasado se ha hecho latente la preocupación por el medio ambiente a nivel global, uno de los principales antecedentes se dio en el año de 1987 con el Informe Brundtland llamado Nuestro Futuro Común, en el cual se plantea la posibilidad de obtener un crecimiento económico basado en políticas de sostenibilidad y expansión de los recursos ambientales (Naciones Unidas, 1987). Desde entonces, existe una preocupación por la problemática relacionada con la pobreza, el cuidado del medio ambiente, social, cultural, causado precisamente por el crecimiento generado por el turismo, el cual en esos años estaba basado en un desarrollo básicamente económico.

Es por eso que en el Informe Brundtland, el TS se puede concebir como el satisfacer las necesidades de turistas y regiones anfitrionas de hoy, a la vez que se protegen y mejoran las oportunidades del futuro, debiendo dar un uso óptimo a los recursos ambientales, respetar la autenticidad sociocultural de las comunidades anfitrionas, asegurar las actividades económicas viables a largo plazo que las beneficien y aportar un alto grado de satisfacción a los turistas mediante experiencias significativas (Masri y Robles, 1997).

Es evidente que el turismo tiene grandes ventajas que han permitido que diversos países alrededor del mundo tengan economías que se fortalecen por esta actividad, como es el caso de México, que en 2017 alcanzó el sexto lugar en cuanto a llegadas de turistas internacionales (UNWTO, 2018). Sin embargo, además de efectos positivos también se generan grandes inconvenientes que son derivados por la gran afluencia de turistas o de la falta/mala planeación y logro de objetivos. Es así como surge el TS con la intención de satisfacer las necesidades de los turistas de hoy y que a la vez que se protejan para satisfacerlas en el futuro (Naciones Unidas, 1987).

Para ello, en la Agenda 21 para el turismo mexicano se destaca la importancia de la gestión local, como el mejor camino para trabajar hacia el desarrollo sostenible ya que nadie conoce mejor los problemas que quienes viven en los destinos, por lo que a través de la participación ciudadana, empresarial y gubernamental se conjuntan esfuerzos para el bien común (SECTUR-SEMARNAT, 2013). En ese sentido, una de las manifestaciones del desarrollo se refiere a los cambios de funciones en el ámbito rural desde la economía del turismo, lo cual conlleva a un perfil productivo local distinto, transformación del mercado de trabajo, cambios de ocupación y uso del suelo, todo ello ocurre en localidades rurales que cuentan con recursos y patrimonio histórico, ambiental y cultural; se trata de un caso particular de ventajas comparativas con atributos culturales y ambientales (Hoyos y Hernández, 2008). 


\subsection{Estrategias para el desarrollo del turismo sostenible en México}

Son diversas las estrategias para el desarrollo del TS que se han puesto en marcha en México, primero porque el TS es una gran oportunidad por la gran riqueza natural con que cuenta el país, y a la vez esto representa una oportunidad para impulsar el turismo en espacios que son demandados con un valor agregado como son los Pueblos mágicos y las ANP. Lo anterior hace congruencia con la agenda 21 para el turismo mexicano que destaca la importancia de la gestión local entre gobierno, empresas y población local para el bien común (SECTUR-SEMARNAT, 2013).

De acuerdo con SECTUR (2014) los Pueblos Mágicos buscan rescatar los atributos y valores histórico-culturales de las comunidades rurales y destinos turísticos en México resaltando sus tradiciones, beneficiando a la comunidad local y presentando alternativas frescas y diferentes bajo la óptica de la sostenibilidad. Lo anterior obliga a la participación de diferentes actores. Lo mismo pasa con las ANP y sus zonas de influencia, en ese sentido Bezaury-Creel y Gutiérrez (2009), consideran que las ANP constituyen la mejor herramienta con que cuenta México para conservar la biodiversidad y los servicios ambientales, entre ellos los culturales, relacionados directamente con el TS.

\subsubsection{Pueblos mágicos}

El Programa de Pueblos Mágicos fue desarrollado como parte de la política turística que actúa directamente sobre las localidades como una marca distintiva del turismo de México, son localidades que requieren orientarse para fortalecer y optimizar el aprovechamiento racional de sus recursos y atractivos naturales y culturales, fortalecer su infraestructura, la calidad de los servicios, la innovación y desarrollo de sus productos turísticos, el marketing y la tecnificación, en suma acciones que contribuirán a detonar el crecimiento del mercado turístico. El objetivo de este programa es "fomentar el desarrollo sustentable de las localidades poseedoras de atributos de singularidad, carácter y autenticidad a través de la puesta en valor de sus atractivos, representados por una marca de exclusividad y prestigio teniendo como referencia las motivaciones y necesidades del viajero actual" (SECTUR, 2014).

Uno de los elementos fundamentales en la actualización en los lineamientos del Programa Pueblos Mágicos del 2014, es el énfasis en la sostenibilidad para la incorporación y permanencia en este programa. Se manifiesta que es necesario para la operación del programa que cada Pueblo Mágico atienda y monitoree la sostenibilidad de la localidad, con base en indicadores básicos, lineamientos, planes, estrategias, estudios locales, etc. que permitan conocer y evaluar el comportamiento de la actividad turística con el apoyo de sus autoridades estatales y con la orientación de la Secretaría de Turismo.

\subsection{2. Áreas Naturales Protegidas}

De acuerdo con la Ley General de Equilibrio Ecológico y Protección al ambiente (LGEEPA), las ANP son las zonas del territorio nacional sobre las que la nación ejerce su soberanía y jurisdicción, en donde los ambientes originales no han sido significativamente alterados por la actividad del ser humano o que requieren ser preservadas y restauradas (DOF, 2018:2). En esta Ley se consideran nueve tipos de ANP: Reservas de la biósfera, Parques nacionales, Monumentos nacionales, Áreas de protección de recursos naturales, Área de protección de flora y fauna, Santuarios, Parques y reservas estatales, Zonas de conservación ecológica municipales y Áreas destinadas voluntariamente a la conservación.

Sobre los parques nacionales, la LGEEPA en su artículo 50, establece que se constituirán, tratándose de representaciones biogeográficas, a nivel nacional, de uno o más ecosistemas que se signifiquen por su belleza escénica, su valor científico, educativo, de recreo, su valor histórico, por la existencia de flora y fauna, por su aptitud para el desarrollo del turismo, o bien por otras razones análogas de interés general (DOF, 2018). En este sentido, el Parque Nacional Bahía de Loreto (PNBL) integra diversos ecosistemas que albergan una gran variedad de hábitats y comunidades biológicas, que involucran procesos ecológicos complejos. Estas características dan origen a valores escénicos, científicos, educativos y recreativos, que favorecen el desarrollo turístico y pesquero, entre otros (SEMARNAP-CONANP, 2000).

\section{Materiales y métodos}

\section{1. Área de estudio}

El municipio de Loreto; homólogo de la localidad de Loreto y cabecera municipal, cuenta con una extensión territorial de 4,878 Km2 pertenece al estado de BCS en México (Soares, 2003), es el más pequeño de los cinco municipios que conforman este estado. La fundación de la ciudad de Loreto está íntimamente ligada con la creación de la Misión de Nuestra Señora de Loreto a finales del siglo XVII 
(SEMARNAP-CONANP, 2000). La ubicación y características de Loreto lo hacen ideal para el desarrollo turístico cultural y de naturaleza. Cuenta con grandes extensiones de playas, así como gran riqueza natural y cultural, por ello en 2012 obtuvo el distintivo del Programa Pueblos Mágicos de México.

Loreto es considerada como una de las principales ciudades del estado de BCS, se encuentra en la parte central de esta entidad por el Golfo de California (también conocido como Mar de Cortés), se ubica a $354 \mathrm{~km}$ al norte de La Paz (Gob. BCS, 2019), capital del estado, colinda al norte con el municipio de Mulegé y el Golfo de California; al este con el Golfo de California; al sur y oeste con el municipio de Comondú (ver figura 1).

Las principales vías de acceso con que cuenta Loreto son la carretera transpeninsular, hacia el norte y sur de la península; el aeropuerto internacional de Loreto y la vía marítima, que cuenta con un muelle de altura en Puerto Escondido y tiene capacidad para recibir embarcaciones, de tipo turístico, principalmente, y de pesca comercial (SEMARNAP-CONANP, 2000).

Figura N. ${ }^{\circ} 1$ Ubicación geográfica de Loreto, Baja California Sur, México

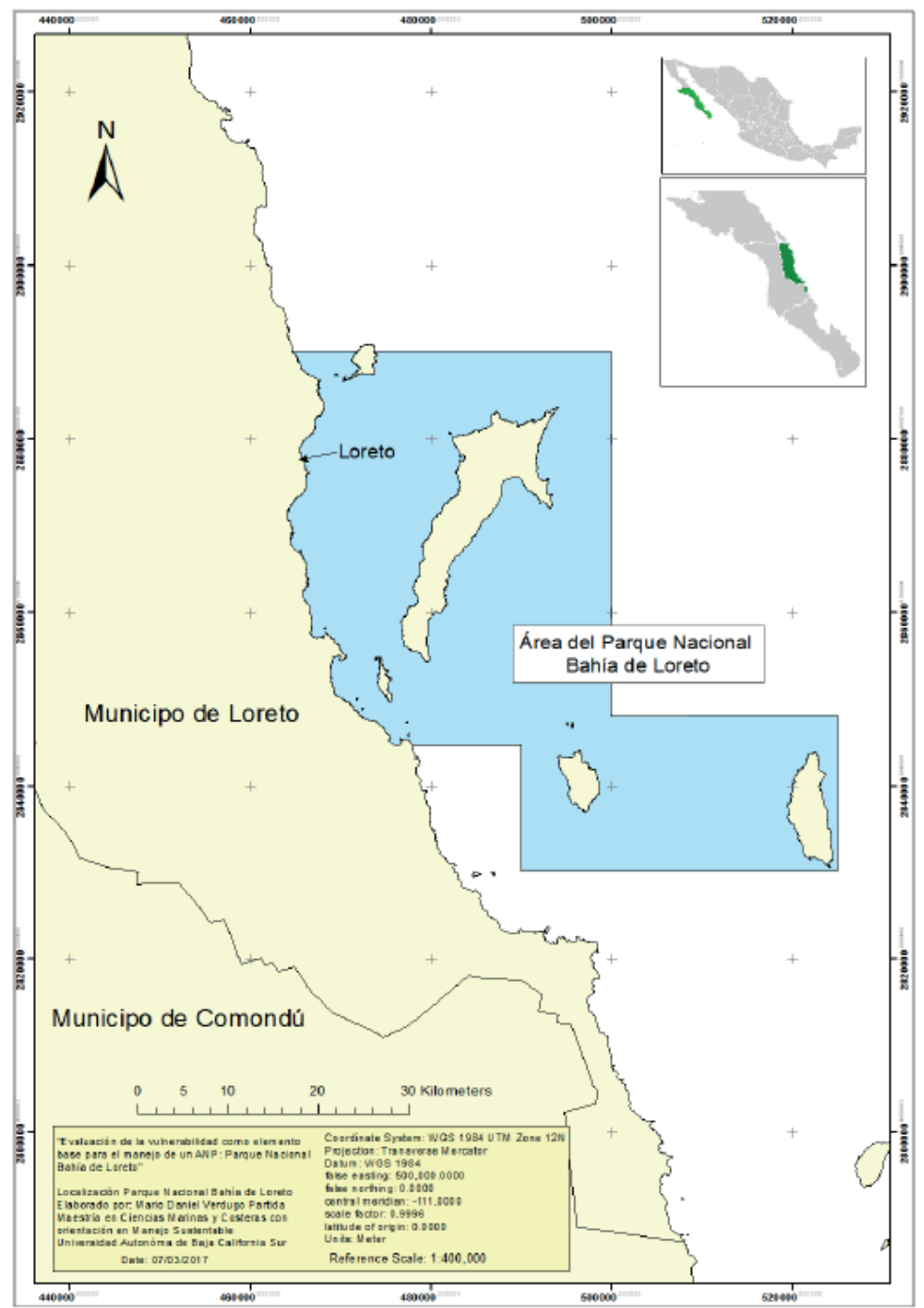

Fuente: Verdugo (2017). 
Desde 1996, Loreto forma parte de la zona de influencia del PNBL donde se localizan las islas Coronados, del Carmen, Danzante, Montserrat (conocida localmente como Montserrato) y Santa Catalina (o Catalana), además de varios islotes. La superficie total del Parque es de 206,580.75 hectáreas, de ésta, las islas e islotes ocupan alrededor del 11.9\% y el resto del área, el 88.1\%, es en su totalidad marina. Se caracteriza por presentar una gran variedad de ambientes costeros marinos con fondos rocosos, arenosos, playas, cañadas, cañones submarinos y terrazas marinas. Se encuentran además una gran variedad de hábitats con una elevada diversidad biológica ya que aquí confluyen diversas poblaciones de especies marinas. En el Parque se encuentran sitios con vestigios paleontológicos, arqueológicos e históricos de gran valor para la investigación científica, histórico y cultural como talleres líticos (donde se realizaba producción de herramientas de piedra (rocas y minerales)) y concheros (sitios donde se practicaban danzas prehispánicas) en las islas Del Carmen y Montserrat que son registro de los periodos de poblamiento prehispánico (SEMARNAP-CONANP, 2000).

Además, se encuentran restos de misiones jesuíticas como las de Ligüí, Loreto y San Javier, construidas durante los siglos XVII y XVIII; y antiguas freideras (utilizadas para extraer la grasa de las ballenas que para el efecto eran cazadas) como la que se encuentra en Isla Montserrat. Todos estos sitios tienen además un importante valor para el turismo que visita la región y que se interesa por su patrimonio cultural y religioso (SEMARNAP-CONANP, 2000).

\subsection{Decisiones metodológicas}

El presente trabajo se desarrolló desde una perspectiva de estudio de caso. Un estudio de caso se caracteriza porque en este se realiza un análisis intensivo y descripciones de una sola unidad o sistema limitado por el espacio y el tiempo, así mismo a través de este tipo de estudio el investigador espera obtener una comprensión más profunda de las situaciones y significados para los involucrados (Hancock y Algozzine, 2006). De acuerdo con Rodríguez (2010) su importancia radica en que es un método articulador del dato y la teoría y que a través de este se puede describir en forma rigurosa una situación social explicando sus factores y componentes.

Dadas las características del fenómeno a estudiar este acercamiento permitió un abordaje mas profundo en cuanto a las motivaciones y el actuar de los actores participantes brindando una perspectiva idónea para entender de forma clara la situación actual del destino turístico y sus posibles tendencias.

A la par de lo anterior se adopta un enfoque de tipo cualitativo descriptivo; esto con la intención de conocer el fenómeno de la actividad turística y cómo se manifiesta; incluye rasgos, cualidades y atributos de la población objeto de estudio (Hernández, Fernández y Baptista, 2014). Se realizó una revisión bibliográfica como herramienta para describir el contexto socioeconómico y ambiental de Loreto. Dentro de la descripción, se realizó un análisis de la oferta y demanda turística para contextualizar el área de estudio que se delimita a la zona turística de Loreto abarcando su centro histórico, la zona hotelera del lugar y playa. Asimismo, para conocer los motivos del viaje, el perfil del turista, los recursos del viaje y la percepción del turista sobre el desempeño de la actividad turística rumbo a la sostenibilidad, se aplicó una encuesta a partir de una muestra estadística representativa en marzo de 2019.

Para determinar el tamaño de dicha muestra, se utilizó la recomendación de Calero (1978) ya que se trata de un análisis de fenómeno social aunado a que se utilizarán escalas nominales para verificar la ausencia o presencia del fenómeno a estudiar. Dicha muestra estadística se estimó con un error estándar del 10\% y 95\% de confiabilidad mediante la siguiente fórmula:

$$
n=\frac{n^{\prime}}{1+\frac{n^{\prime}}{N}}
$$

Donde

$\mathrm{n}=$ tamaño de la muestra

$\mathrm{n}^{\prime}=$ varianza muestral entre varianza poblacional $\quad \mathrm{n}^{\prime}=\mathrm{S}^{2} / \sigma^{2}$

$\mathrm{N}=$ población total

$$
\mathrm{n}^{\prime}=\mathrm{S}^{2} / \sigma^{2}
$$

$\mathrm{S}^{2}$ se determina en términos de probabilidad en base a: $\quad \mathrm{S}^{2}=\mathrm{p}(1-\mathrm{p})$

Donde $\mathrm{p}=$ nivel de confianza $95 \%$

$\sigma^{2}$ se determinó en base a: $\quad \sigma^{2}=(s e)^{2}$ (varianza poblacional)

Donde $(s e)^{2}=$ error estándar al cuadrado 
Dado lo anterior, y de acuerdo con datos del Gobierno del estado de Baja California Sur (2018), el total de turistas en Loreto en el año 2016 fue de 107,218, por lo que una vez aplicada la formula la muestra estadística es de 96 .

\subsection{Trabajo de campo}

El trabajo ce campo se realizó durante marzo de 2019, se aplicaron encuestas, se hicieron entrevistas y reportes de observación no participante. Para la obtención de datos sobre la percepción del turista se aplicaron 96 encuestas de manera personal en las principales zonas de afluencia, se consideraron variables nominales, ordinales y de intervalo. La encuesta está dividida en cuatro secciones: 1) perfil del turista, 2) motivos del viaje, 3) recursos del viaje, y 4) atractivos y componentes turísticos. El tiempo máximo de aplicación fue de 10 minutos por persona. Se utilizó el muestreo probabilístico. La muestra fue integrada por los turistas mayores de 18 años que tuvieron contacto con los servicios del destino turístico de Loreto (al menos debieron haber estado tres horas en el lugar).

Por otro lado, para conocer la percepción de los actores clave, se efectuaron siete entrevistas semiestructuradas las cuales se dirigieron a temas relativos a: i) sustentabilidad, ii) involucramiento de la población local en proyectos sustentables, iii) oferta turística (hoteles, actividades turísticas, ferias, atractivos, eventos deportivos, religiosos, culturales y actores involucrados), iv) demanda turística (perfil del turista, motivos de viaje y recursos contratados), v) educación ambiental de la comunidad, vi) calidad y cantidad de los atractivos naturales, y vii) cuidado y conservación de los atractivos naturales y culturales. Las entrevistas se aplicaron a miembros del Comité ciudadano del Pueblo Mágico, empresarios del sector turístico, funcionarios públicos municipales, estatales y federales y una asociación civil ambientalista. Se buscó la representatividad de los diversos actores involucrados a partir del método estadístico bola de nieve que hacen referencia Martín-Crespo y Salamanca (2007). El nivel de saturación se determinó al punto en que, al agregar nuevos testimonios, el conocimiento incremental sobre el fenómeno era mínimo de acuerdo con la recomendación de Eisenhardt y Graebner (2007).

Finalmente, los datos fueron complementados a partir de seis reportes de observación directa no participante que incluyen información sobre infraestructura turística, infraestructura social, servicios públicos, desarrollo local, cultura, sociedad y medio ambiente. Cabe mencionar que en el análisis de resultados se presentan porcentajes de dichas observaciones.

Las limitaciones del estudio se identifican en el margen de tiempo que se utilizó en la recogida de datos ya que siendo un sitio turístico el flujo de turistas es por temporadas, lo que implicaría el tener que extender la investigación a todo un ciclo anual cuando menos. Otro aspecto limitante es el acceso a información relevante en manos de tomadores de decisiones, especialmente del gobierno local que solo facilitó de forma parcial. Sin embargo, la información obtenida se considera válida para mostrar aspectos relevantes del fenómeno estudiado.

\section{Resultados}

\subsection{Oferta turística}

De acuerdo con Leiva y Rivas (1997), la oferta turística está integrada por tres componentes básicos: atractivos turísticos, planta turística, e infraestructura. Estos pueden ser puestos en el mercado mediante procesos de gestión, desarrollados por los empresarios turísticos, por las propias municipalidades y por otros actores. La oferta turística debe estar disponible en el mercado para ser usados o consumidos por los turistas.

Aunque Loreto es un destino turístico pequeño ofrece diversas actividades turísticas, empresas de alojamiento y restauración. Los establecimientos de hospedaje registrados en Loreto, según INEGI (2017) son 39, los cuales son de las siguientes categorías: 27 son hoteles, 3 moteles, 3 cabañas, 3 campamentos, 2 casas de huéspedes y 1 casa amueblada (ver tabla 1 ). Los anteriores establecimientos en su conjunto conforman la oferta de hospedaje de 1,068 cuartos y unidades de hospedaje; de los cuales $40 \%$ son de 5 estrellas, $16 \%$ de 4 estrellas, $14 \%$ de 3 estrellas, $6 \%$ de 2 estrellas, $13 \%$ de una estrella y $12 \% \sin$ clasificación. En ese sentido y de acuerdo con Cruz et al. (2016), en el año 2013, Loreto contaba con 31 hoteles, por lo que se observa un incremento de 8 hoteles, de 2013 a 2016, así como un incremento de 190 cuartos. 
Tabla N. ${ }^{\circ}$ 1: Establecimientos de hospedaje en Loreto, B.C.S.

\begin{tabular}{|c|c|c|}
\hline Tipo de establecimiento & Núm. de Establecimientos & Cuartos / de hospedaje \\
\hline Hoteles & 27 & 890 \\
\hline Moteles & 3 & 68 \\
\hline Cabañas & 3 & 27 \\
\hline Campamentos & 3 & 61 \\
\hline Pensiones & 2 & 14 \\
\hline Casas amuebladas & 1 & 8 \\
\hline Totales & 39 & 1,068 \\
\hline
\end{tabular}

Fuente: elaboración propia con base en INEGI (2017).

En relación con los establecimientos y servicios de alimentos y bebidas Loreto cuenta con 57, de los cuales están distribuidos en las siguientes categorías: 40 son restaurantes, 9 cafeterías, fuentes de sodas, neverías o refresquerías y 8 bares (INEGI, 2017).

De acuerdo con las encuestas y las entrevistas semiestructuradas, Loreto ofrece diversas actividades turísticas que pueden hacerse en tierra y mar, entre las primeras incluyen: viajes a la isla, excursión, campismo, senderismo, observación de flora y fauna, gastronomía, visitas religiosas, tirolesa, museo, cabalgata, fotografía. Las actividades acuáticas que pueden realizarse son: buceo, snorkel, kayak, viajes en lancha, pesca deportiva y avistamiento ballenas. En ese sentido, las actividades turísticas, que incluyen viajes a las islas del Parque y la costa con embarcaciones de tipo kayak, veleros, yates recreativos, motos acuáticas y cruceros de historia natural, además del buceo, campismo y caminatas, se han ido incrementando considerablemente. Por lo que la oficina administrativa del ANP trabaja en la programación de visitas con el objeto de que el uso de sitios sea ordenado y el impacto causado sobre ellos sea mínimo.

Por otro lado, el kayakismo se ha practicado desde hace más de 40 años en la zona, la oferta de este servicio es en mayoría por compañías extranjeras, mismas que se encuentran registradas y con permisos por la Comisión Nacional de Áreas Naturales Protegidas (CONANP) para ofrecer sus servicios a una creciente demanda de turistas canadienses, norteamericanos y europeos. Los viajes en kayak son generalmente de tipo recreativo y en ocasiones educativo. Las empresas promocionan paquetes con una duración de tres a diez días en promedio, con grupos de dos a diez personas que hacen travesías y acampan en las playas. Aunque también ocurre la renta de kayak donde los viajeros hacen la travesía sin la presencia de un guía, por lo que están menos regulados.

Además, existen cruceros que arriban de Estados Unidos y Canadá donde los cruceristas pernoctan en el Pueblo Mágico de Loreto y realizan actividades de ecoturismo, donde los principales atractivos de estos recorridos son la observación de ballenas (temporada de enero a marzo) y aves. Finalmente, las caminatas en sitios accesibles y representativos del paisaje son parte de las actividades de los viajes en kayak y cruceros y en ellas se incluyen las explicaciones de los guías naturalistas. También las islas son usadas por yates y veleros privados que pasan dos o tres días anclados en alguna de las ensenadas y bahías de las islas del Parque, haciendo visitas esporádicas a las playas y zonas terrestres.

\subsection{Demanda turística}

La demanda turística comprende el total de personas que viajan y usan las instalaciones y servicios turísticos ubicados en lugares distintos al de residencia y trabajo de los usuarios (Leiva y Rivas, 1997). De acuerdo con INEGI (2017) en cuanto a las llegadas de turistas que usan alojamiento en Loreto en 2016 se alcanzó la suma de 107,218 de los cuales el 65\% corresponde a nacionales y el $35 \%$ a extranjeros, de los cuales el $23 \%$ corresponde a hospedaje de 5 estrellas, el $15 \%$ de 4 estrellas, $22 \%$ de 3 estrellas y el $41 \%$ de una estrella (ver tabla 2). El porcentaje de ocupación hotelera para ese mismo periodo es de $31 \%$ con una estadía promedio de 1.9 días. Cabe mencionar que de acuerdo con Cruz et al. (2016) en el año 2013, Loreto recibió un total de 90,190 turistas observándose un incremento de $16 \%$ para el año 2016. 
Tabla N. ${ }^{\circ}$ 2: Llegadas de turistas con alojamiento en Loreto, B.C.S. (2016)

\begin{tabular}{|c|c|c|c|c|c|c|}
\hline Procedencia & $\begin{array}{c}\text { Número de } \\
\text { turistas }\end{array}$ & \multicolumn{5}{|c|}{ Tipo de alojamiento } \\
\hline Nacionales & 69,657 & \multicolumn{5}{|c|}{ Número de estrellas } \\
\hline Extranjeros & 37,561 & 5 & 4 & 3 & 2 & 1 \\
\hline Totales & 107,218 & 24,208 & 15,879 & 23,355 & ND & 43,776 \\
\hline
\end{tabular}

Fuente: elaboración propia con base en INEGI (2017).

\subsection{Perfil del turista y motivos del viaje}

Es menester mencionar que para algunas variables del presente estudio se realiza una comparación con una investigación realizada en Loreto en el año 2014 y publicada por Cruz et al. en 2016, indicando si hubo variación positiva o negativa en su desarrollo en un periodo de tiempo de 5 años. Se inicia con el perfil del turista, y de acuerdo con los resultados obtenidos en las encuestas, sobre el género el $49 \%$ de las personas que visitan Loreto son hombres y el 50\% mujeres, el 29\% proceden de México, el 46\% de Estados Unidos, el 16\% de Canadá y se tiene un $9 \%$ de turistas que visita esta comunidad de otras partes del mundo. En contraste con un estudio realizado por Cruz et al. (2016), sobre el lugar de procedencia, encontraron que en 2014 el turista nacional se componía del $56 \%$ del total y $44 \%$ extranjero (Estados Unidos y Canadá principalmente), se observa que el turista nacional ha disminuido 27 puntos porcentuales y el internacional ha aumentado ya que para 2019 suman el 79\% indicando un cambio importante en la composición del turista.

Respecto a las edades de los turistas, para el año 2019, el $9 \%$ tiene entre 10 y 18 años, el $10 \%$ entre 26 y 33 , el $4 \%$ entre 42 y 48, el $15 \%$ entre 49 y 55, el $13 \%$ entre 56 y 63 y el $44 \%$ son de más de 64 años. De los turistas encuestados el $38 \%$ viaja con su cónyuge, el $30 \%$ en familia, $3 \%$ con compañeros de

Tabla N. ${ }^{\circ}$ 3: Perfil del turista de Loreto, B.C.S.

\begin{tabular}{|c|c|c|}
\hline $\begin{array}{c}\text { Característica } \\
\text { Demográfica }\end{array}$ & Categoría & Porcentaje \\
\hline \multirow{3}{*}{ Género } & Mujer & $49 \%$ \\
\hline & Hombre & $50 \%$ \\
\hline & Otro & $2 \%$ \\
\hline \multirow{4}{*}{ Procedencia } & México & $29 \%$ \\
\hline & Estados Unidos & $46 \%$ \\
\hline & Canadá & $16 \%$ \\
\hline & Otro & $9 \%$ \\
\hline \multirow{7}{*}{ Edad (años) } & $18-25$ & $9 \%$ \\
\hline & $26-33$ & $10 \%$ \\
\hline & $34-41$ & $4 \%$ \\
\hline & $42-48$ & $5 \%$ \\
\hline & $49-55$ & $15 \%$ \\
\hline & $56-63$ & $13 \%$ \\
\hline & 64 y más & $44 \%$ \\
\hline \multirow{5}{*}{$\begin{array}{l}\text { Acompañantes de } \\
\text { viaje }\end{array}$} & Cónyuge & $38 \%$ \\
\hline & Familia & $30 \%$ \\
\hline & Compañeros de trabajo & $3 \%$ \\
\hline & Amigos & $19 \%$ \\
\hline & Solo & $10 \%$ \\
\hline
\end{tabular}

Fuente: elaboración propia con base en las entrevistas. 
trabajo, el $18 \%$ con amigos y un 10\% viaja solo (ver tabla 3). Por otro lado, para el año 2014 y de acuerdo con Cruz et al. (2016) las personas que visitaron Loreto acompañados del cónyuge representaron el $16 \%$, con familia $47 \%$ con amigos $21 \%$ y solos $10 \%$, en ese sentido se observa que se ha incrementado con 22 puntos porcentuales el número de personas que visitan el área de estudio acompañados de su cónyuge y ha disminuido con 17 puntos porcentuales los que se acompañan con la familia, por lo que a composición del acompañante ha cambiado a favor de ser un destino de parejas.

Sobre los motivos de viaje de los turistas de Loreto el 7\% lo hace por visitar a la familia (turista nacional y residencial), el 75\% con el objetivo de descansar (turista extranjero), el 9\% por negocios, el $1 \%$ para participar en eventos culturales/religiosos, otro $1 \%$ a eventos sociales y un $7 \%$ por diferentes motivos a los anteriores.

Las actividades que realizaron los turistas encuestados fueron las siguientes: $20 \%$ caminata por el pueblo, $13 \%$ por la plaza principal, 11\% consume alimentos regionales, $10 \%$ sitios históricos, $9 \%$ actividades de turismo alternativo, $9 \%$ sitios históricos, $8 \%$ sitios religiosos, $5 \%$ tiendas y artesanías, $5 \%$ sitios famosos, $3 \%$ actividades deportivas y $1 \%$ vida nocturna.

\subsection{Recursos del viaje}

Se entiende como recursos del viaje aquellos servicios que el turista ha contratado en el destino, incluyen recursos naturales, culturales y sociales que hayan usado, aunque no hayan pagado por ellos. En ese sentido, sobre el servicio de hospedaje y de acuerdo con las encuestas el $42 \%$ de los turistas contrataron el servicio de hotel seguido de la casa de huésped con $8 \%$ de los casos, $7 \%$ contrató un hostal al igual que tráiler park. Cabe mencionar que $16 \%$ de los encuestados se hospedaron en casa de familia, $7 \%$ en casa propia y $5 \%$ no contrataron servicio de hospedaje. Finalmente $6 \%$ de los turistas pronunciaron haber contratado servicio de hospedaje a partir de AirBnb. En contraste con lo encontrado por Cruz et al. (2016) en 2014, se observa que $65 \%$ contrató hotel, $12 \%$ casa de huéspedes y $21 \%$ otro. El principal cambio que se observa es la disminución del servicio de hospedaje del hotel en 23 puntos porcentuales en el periodo de 2104 al 2019.

Sobre el servicio de medios de transporte $35 \%$ de los turistas reportan haber llegado a Loreto en auto propio, seguido de auto rentado (25\%) y de avión (22\%). Se observa que del periodo 2014 al 2019 existe una disminución de las llegadas a Loreto en avión ya que Cruz et al. (2016), reportan que en 2014, 39\% de los turistas llegaron en avión y 49\% en auto, reportando un incremento de 19 puntos porcentuales en este último medio de transporte.

Sobre el servicio de alimentos y bebidas, $61 \%$ de los turistas contratan restaurantes, cafeterías y loncherías, seguido de 33\% que contrataron servicio de alimentos en bares, mercados y cadenas de alimentos. Los turistas reportaron que $38 \%$ contrataron servicio de museos, $12 \%$ festival de música y actividades religiosas, $5 \%$ dijo haber contratado servicios para la asistencia a festival de cine y teatro. Finalmente, $23 \%$ dijo no haber contratado ningún servicio de este tipo.

Adicionalmente, en el caso de las actividades recreativas y de esparcimiento los turistas reportan haber realizado fotografía con el $27 \%$ de los casos, $23 \%$ de ellos realizaron observación de flora y fauna, $18 \%$ dicen haber realizado actividades recreativas relacionadas con el parque marino tales como avistamiento de ballenas, tour a las islas en bote o panga, visita a la playa; finalmente, $16 \%$ realizó senderismo. Se observa que todas las actividades reportadas están estrechamente ligadas con el uso de los recursos naturales y que son susceptibles de revisar si dichas actividades se practican responsablemente con un enfoque de sostenibilidad.

\subsection{Caracterización de los atractivos y componentes turísticos}

Se presentan los resultados de la percepción de los actores clave y del turista sobre aspectos relacionados con los atractivos y componentes turísticos del destino de Loreto, especialmente se rescatan recursos relacionados con la calidad, conservación, actividades, limpieza, seguridad, hospitalidad y satisfacción del turista.

En primer lugar, de acuerdo con las entrevistas semiestructuradas aplicadas a los actores clave se observa que la actividad turística de Loreto está estrechamente relacionada con la planeación del Municipio de Loreto (en mayor medida) y del Comité ciudadano del Pueblo Mágico (en menor medida) quienes en sus estrategias y actividades resaltan la importancia histórico-cultural de la zona de estudio. Además, dicha planeación turística tiene estrategias comunes y paralelas con la Comisión Nacional de Áreas Naturales Protegidas (CONANP) desde el año1996 cuando fue declarada como ANP; cabe mencionar que dicha declaratoria fue muy bien recibida por la sociedad loretana. Algunas de las estrategias de manejo y conservación del Parque son los permisos para ecoturismo, conservación, vigilancia y pago de derechos. Asimismo, se trabaja con la población local en estrategias de educación 
ambiental específicamente de parte de la Asociación Civil EcoAlianza. No obstante, hace falta evaluación y seguimiento, así como financiamiento.

Los entrevistados comentan que el Parque cuenta con distintos atractivos turísticos gracias a la flora y fauna endémica de las islas que lo conforman. Uno de los atractivos más conocidos es el avistamiento de ballenas ya que Loreto es el santuario de la ballena azul y la pesca deportiva. Al respecto comentan que como parte de las estrategias de sostenibilidad trabajan de la mano con la Procuraduría de Protección al Ambiente (PROFEPA) en la vigilancia del Parque Nacional. Además, comentan que a pesar de que dentro de los lineamientos del Pueblo Mágico se contempla la sostenibilidad del sitio, el comité ciudadano del Pueblo Mágico no ha podido implementar estrategias dirigidas a ello, ya que la falta de recursos económicos los limita, sin embargo, la ciudadanía y otras organizaciones de la sociedad civil trabajan en proyectos de educación ambiental exitosos, con la población local. Asimismo, algunos hoteles están capacitándose, y otros ya están capacitados, para realizar prácticas sostenibles como la reducción y reutilización de desechos sólidos y ahorro de energía y agua. Sobre la limpieza de las calles y del Pueblo Mágico se trabaja arduamente con servicios públicos municipales quienes limpian y hacen recolección de basura todos los días en el primer cuadro de la ciudad y zona turística con la finalidad de que el turista se lleve una buena imagen.

Los informantes también comentan que un atractivo cultural y religioso de Loreto es la visita a la Misión de San Javier, sitio al que se llega en auto en un espacio de tiempo de 20 minutos desde el centro de Loreto. La visita a esta misión es una tradición y está arraigada para la población sudcaliforniana y ha sido secundada por la mayoría de los turistas que llegan al sitio, según registros de la iglesia de San Javier, se reciben visitas todos los días, pero éstas se concentran del 1 al 3 de diciembre cuando se celebran las fiestas patronales (celebrada desde hace más de 300 años), se comenta que en dichas fechas el lugar es rebasado por la demanda de servicios turísticos ya que es un pueblo de 140 habitantes y recibe aproximadamente ocho mil turistas concentrados en tres días en un espacio limitado por lo que la generación de basura, el desmonte de sitios para dar lugar a renta de piso para acampado, el uso y demanda de agua y los sitios naturales se ven afectados por la capacidad de carga del destino turístico, incluso se percibe que se atenta contra el propio patrimonio cultural-religioso. Además, se percibe que la fiesta patronal ha cambiado de objetivo ya que actualmente gran parte de los turistas que arriban en dicha fecha lo hacen con la finalidad de abusar de la ingesta de bebidas alcohólicas sin restricción alguna lo que ha causado problemas sociales, culturales y ambientales. Lo anterior deja ver que dicho evento esta desorganizado y carece de reglamento de uso de suelo y de reglas de convivencia, además ha perdido su identidad y objetivo.

No obstante, en el Pueblo Mágico de Loreto, las actividades de senderismo, avistamiento de aves, kayak, tours a las islas se organizan de tal forma que se anuncian como actividades de bajo impacto tomando en cuenta la disminución de la huella ecológica del turista, sobre todo en las actividades que se hacen en el PNBL. Los turistas que ingresan al Parque deben pagar el precio del brazalete que les da derecho de entrada, conocido por la CONANP como "cobro de derechos", además de que, antes de ingresar, se les brinda una plática de educación ambiental con énfasis en el turismo responsable.

En segundo lugar, con relación a los resultados de la encuesta realizada a los turistas, se hace un análisis a partir de diferentes factores socioeconómicos, culturales y de naturaleza relacionados con la actividad turística. La tabla número 4 muestra los componentes evaluados con sus diferentes calificaciones que van desde excelente, buena, mala y pésima. En el caso de la calificación de "excelente" con el más alto porcentaje de percepción sobresalen la hospitalidad (68\%), seguridad ciudadana (64\%), limpieza de calles y áreas públicas (62\%), seguidos del cuidado y conservación de los atractivos naturales y culturales (56\% y 56\% respectivamente). Los componentes que sobresalen en la calificación de "bueno" son calidad de actividades culturales (55\%) y calidad en los servicios turísticos (53\%). Se puede observar que prácticamente todos los componentes evaluados obtuvieron una calificación alta en la escala de prioridades según su percepción. De acuerdo con las entrevistas, lo anterior refleja el trabajo conjunto de autoridades, empresarios y sociedad civil en acciones a favor de la calidad y la conservación del destino con el fin de cumplir con los parámetros indicados en la denominación de Pueblo Mágico. Esto se combina con la vigilancia y disposición de autoridades para regular el trasiego de turistas en lugares dentro del PNBL en la que se encuentra enclavado Loreto.

En relación con lo anterior, en el estudio realizado por Cruz et al. (2016) los turistas califican entre 8 y 8.9 (en una escala del 0 al 10) a la limpieza de calles y áreas públicas, asimismo, 97\% de ellos dijo no haber sufrido atentado contra su seguridad por lo que el rubro de la seguridad es favorecido. Los resultados obtenidos en 2019 se refuerzan con lo encontrado en 2014 en los rubros de seguridad ciudadana, y limpieza de calles y áreas públicas así como la satisfacción del turista que llegó a la calificación de 8 (turistas satisfechos) desafortunadamente para este estudio no se encontró algún otro documento donde se pueda contrastar los demás recursos evaluados en esta sección en el año 2019. 
Tabla N. ${ }^{\circ}$ 4: Evaluación de los componentes turísticos

\begin{tabular}{|l|c|c|c|c|}
\hline \multirow{2}{*}{ Componentes evaluados } & \multicolumn{3}{c|}{ Calificación (Porcentaje) } \\
\cline { 2 - 5 } & Excelente & Buena & Mala & Pésima \\
\hline Calidad de los servicios turísticos (general) & 45 & 53 & 2 & 0 \\
\hline $\begin{array}{l}\text { Calidad y conservación de los atractivos turísticos } \\
\text { (general) }\end{array}$ & 50 & 47 & 3 & 0 \\
\hline Calidad de actividades recreativas y de esparcimiento & 47 & 44 & 9 & 0 \\
\hline Calidad de actividades culturales & 36 & 55 & 8 & 1 \\
\hline $\begin{array}{l}\text { Cuidado y conservación de los atractivos naturales } \\
\text { (general) }\end{array}$ & 56 & 39 & 5 & 0 \\
\hline $\begin{array}{l}\text { Cuidado y conservación de los atractivos culturales } \\
\text { (general) }\end{array}$ & 56 & 39 & 5 & 0 \\
\hline Conservación de áreas públicas & 47 & 44 & 8 & 0 \\
\hline Limpieza de calles y áreas públicas & 62 & 31 & 7 & 0 \\
\hline Atención turística en general (hospitalidad) & 68 & 29 & 3 & 0 \\
\hline Satisfacción del turista & 52 & 37 & 11 & 0 \\
\hline
\end{tabular}

Fuente: Elaboración propia con base a las encuestas

\subsection{El turismo en Loreto rumbo a la sostenibilidad}

Loreto tiene la ventaja de ser un destino con crecimiento en las visitaciones para la práctica del turismo cultural y de naturaleza, no obstante, algunas situaciones podrían afectar su desarrollo como destino sostenible ya que desafortunadamente, los actores clave coinciden en que los recursos financieros para realizar más acciones orientadas a la sostenibilidad son limitados, por lo que se percibe un avance lento en cuanto a lo que se planea y espera lograr en un periodo de tiempo. Esto ha hecho que el ciudadano común, quienes en su mayoría trabajan en la prestación de servicios turísticos, no perciban los beneficios directos del nombramiento como Pueblo Mágico y de la cercanía con el ANP, ambos con prácticas sostenibles, al menos en acciones aisladas. Según Masri y Robles (1997) aluden a que la comunidad anfitriona de un destino de TS debe contar con un alto grado de satisfacción y beneficios, por lo que Loreto debe trabajar más en ello.

De acuerdo con los resultados de las guías de observación, se hace notar la limpieza y conservación de la zona costera y del centro histórico de Loreto, que aunado al esfuerzo de las autoridades locales se apoya del tipo de turista que llega al lugar, que en su gran mayoría son mayores de 50 años y que de acuerdo con sus comentarios, son conscientes de la importancia de conservar el patrimonio cultural y natural del destino turístico. Sin embargo, en las zonas aledañas al centro histórico, donde no hay mucho trasiego de turistas, se observó un desarrollo urbano deficiente, lo mismo para la limpieza y conservación de áreas públicas. Lo anterior muestra inconsistencia con los lineamientos que debe cumplir un Pueblo Mágico para su incorporación y permanencia, ya que en el acaso de Loreto, se observa una deficiente capacidad infraestructural para toda la localidad y no solo para la zona turística.

Relacionado con lo anterior y en la búsqueda del TS, en las entrevistas se identificaron algunas áreas de oportunidad para mejorar las condiciones y el desempeño de la actividad tales como la adopción de una cultura ambiental en las prácticas de la oferta hotelera, restaurantera y otros servicios turísticos, para lo cual es necesario que los prestadores de servicios turísticos y la población local se capacite por medio de cursos de propósito específico relacionados con la educación ambiental, conservación, preservación y cuidado del medio ambiente y de los recursos naturales, practicas sostenibles, etc.

En este tenor, en Loreto existe una asociación civil llamada Eco-Alianza, es una entidad no lucrativa que busca la conservación de los recursos naturales y el desarrollo sostenible de las comunidades, donde su principal actividad es la participación en diferentes programas, tales como, a) educación ambiental, que se extiende a escuelas de todos los niveles, pero poniendo énfasis en el nivel primaria, donde se imparten talleres de conservación de mamíferos marinos y aves, limpieza de playas y reciclado, entre otros; b) conservación marina, donde se promueve la pesca y el consumo responsable, c) manejo de la almeja chocolata, un producto marino que se busca conservar ya que es ingrediente principal en la gastronomía turística; d) monitoreo continuo de la calidad del agua en playas de la localidad; e) manejo de residuos sólidos, a través de la iniciativa ciudadana "Loreto Ideal" teniendo como meta la eliminación completa de plásticos y popotes en hoteles y restaurantes de la zona, de acuerdo con la Ley del Equilibrio 
Ecológico y Protección del Ambiente del Estado de Baja California Sur, aprobada el 18 de julio de 2018; y, f) participación activa en la Red de Educadores Ambientales de Loreto.

El compromiso de esta asociación se hace notar principalmente por sus labores de educación y concientización sobre el cuidado del medio ambiente donde no solo se involucran a empresarios turísticos, sino a la sociedad en general. Además, es notable la participación de la mencionada Red de Educadores Ambientales en escuelas de la localidad, con el objetivo de enseñar a las nuevas generaciones sobre la necesidad de la sostenibilidad adoptando valores que posteriormente se trasladan a sus hogares, según manifestaron el Director de Eco Alianza y uno de los enlaces con la sociedad civil. Dicho sea de paso, Eco Alianza es promotora de eventos deportivos con captación de turistas nacionales e internacionales y promocionados con la frase "cero basura" en los que han tenido un gran éxito.

$\mathrm{Al}$ ser Loreto una comunidad pequeña, la educación para la sostenibilidad se muestra como una alternativa muy viable para trabajar con diferentes estrategias y diferentes grupos sociales, siempre buscando ser un destino respetuoso del equilibrio natural de los ecosistemas. Sin embargo, hoy en día han sido identificadas algunas problemáticas que limitan el alcance de las metas para la sostenibilidad como las que se mencionan algunos de los entrevistados clave, a saber:

- La actividad turística ha traído un encarecimiento en los bienes raíces y la renta de alojamiento; además, existe una división clara entre los desarrollos habitacionales construidos para los turistas y residentes extranjeros y los locales. De acuerdo con Hoyos y Hernández (2008) la economía del turismo conlleva a cambios en el uso de suelo en localidades rurales, no obstante, dichos cambios deben beneficiar en mayor medida a la comunidad local.

- Se observa la falta de inversión en la reparación del cárcamo de aguas negras para la reparación de fugas y reducción de la contaminación. Lo mismo pasa para el procesamiento de lodos de la planta tratadora de agua residual lo que constituye un impacto ambiental. De acuerdo con la OMT (2005 y 2006) una de las características de un destino sostenible es el cumplimiento de un sistema eficiente de manejo de desechos sólidos y líquidos.

- El manejo del comité del Pueblo Mágico se ha politizado y en la actualidad la planeación para el desarrollo del turismo se decide, en su mayoría, por la administración municipal, aunque se permite la participación de empresarios y comunidad; lo anterior hace que la mayor parte de las decisiones importantes provengan de la administración municipal. Hay que recordar que el papel que juega el Comité del Pueblo Mágico es el de la toma de decisiones para el desarrollo del turismo por lo que debe haber mayor participación en lo antes dicho. De acuerdo con la OMT (2006) para lograr un TS se necesita tener un proceso continuo donde la participación informada de todos los actores muestre su liderazgo y amplia colaboración en un consenso. Asimismo, SECTUR (2014) menciona que para la planeación del turismo es necesario tener en cuenta las necesidades y opiniones de todos los actores locales y las motivaciones y necesidades del viajero.

- El nombramiento de Pueblo Mágico no ha traído beneficios tangibles en cuanto a la inversión gubernamental necesaria para la gestión del TS, tampoco ha aportado a la solución de problemas ambientales como el cuidado y conservación de playas. Aunque Loreto es parte de la zona de influencia del PNBL, el recurso destinado al cuidado y protección de playas es limitado, por un lado el tener una categoría de protección atrae turistas de naturaleza, por otro lado, de acuerdo con la OMT (2006) para tener las características de un destino para le TS, es necesario el uso óptimo de los recursos naturales, así como poner en práctica las medidas preventivas o correctivas necesarias, identificadas por los actores locales, destacando la gestión local, ya que de acuerdo con SECTUR-SEMARNAT (2013), nadie conoce mejor los problemas que quienes viven en los destinos turísticos quienes deben buscar el bien común para la población local y para el turista.

- Es necesaria la concientización de empleados y dueños de establecimientos turísticos sobre la importancia de pertenecer al Programa de Pueblos Mágicos, a falta de ella, se fomenta la pérdida de identidad, más que la adopción de ella como requisito de la sostenibilidad. De acuerdo con SECTUR (2014) es necesaria la identidad cultural como característica de un destino para el TS.

- La participación de autoridades federales en labores de conservación, cuidado e inspección del sitio son muy irregulares y con un apoyo marginal en cuanto a los recursos financieros destinados para estos fines. Asimismo, la planeación de las actividades turísticas y el cuidado del entorno para ello es aislado. De acuerdo con la OMT (2006) es necesario asegurar actividades económicas viables y a largo plazo, contar con la participación y liderazgo político y colaboración amplia para lograr la sostenibilidad del destino. Sobre los recursos financieros, es necesaria la voluntad política.

- En las fiestas que se celebran cada año en la localidad de San Javier, se supera con mucho la capacidad de carga del lugar dejando un daño en el patrimonio cultural y natural, especialmente 
porque ya se perdió la identidad de las fiestas religiosas. De acuerdo con los entrevistados en las fiestas patronales se recibe un aproximado de ocho mil turistas concentrados en dicha localidad, quienes acampan en sitios modificados sin restricción alguna y el número de turistas los que logra hospedarse en Loreto va de acuerdo con la oferta hotelera, que de acuerdo con INEGI (2017) tiene 1,068 cuartos disponibles. Ante lo dicho, la OMT (2005 y 2006) alude que para el TS se debe cuidar la capacidad de carga y reducir la presión sobre el sitio, además debe cumplir con un parámetro que permita uso de suelo óptimo en base a la planificación consensuada sin perder la identidad.

Los puntos anteriores dejan ver las áreas de oportunidad que tienen los tomadores de decisiones de Loreto con el ánimo de cumplir con los requerimientos para la sostenibilidad.

En apoyo a lo anterior, dentro del Programa de manejo del PNBL existe un componente de manejo dedicado al turismo, uso público y recreación al aire libre cuyo objetivo es garantizar la compatibilidad de las actividades turísticas con los objetivos de conservación del ANP, así como promover que las actividades turísticas tengan un impacto mínimo sobre el ambiente donde se debe involucrar al sector turístico como promotor de la educación ambiental y generador de fondos para la conservación del área (SEMARNAP-CONANP, 2000). Por lo que, tal como lo dice la OMT (2006) es necesario trabajar con un proceso continuo con medidas preventivas y correctivas.

Como se puede apreciar, hay todavía un camino por recorrer en la búsqueda de la sostenibilidad; dentro de ese camino, existen posibilidades para que en corto plazo las condiciones mejoren principalmente por la toma de conciencia de los lugareños que se están integrando casi en su totalidad a actividades relacionadas con el turismo cultural y de naturaleza, lo que trae consigo la posibilidad de que se aprecie de una forma muy diferente la forma en que se aprovechan los recursos naturales y culturales del lugar, ya que ahora la conservación y aprovechamiento racional de los recursos son percibidos como necesarios para el mejor desarrollo de la actividad turística sostenible, de acuerdo con lo manifestado por los actores entrevistados.

\section{Conclusiones y recomendaciones}

Loreto conserva como fortaleza sus atractivos culturales y naturales, la seguridad pública y la limpieza de sus áreas públicas y calles. Lo anterior se fortalece con la opinión de los turistas quienes evaluaron a partir de su percepción, dentro de las calificaciones excelente y bueno, aspectos como la hospitalidad, cuidado y conservación de los atractivos culturales y atractivos naturales, así como la calidad de las actividades recreativas y de esparcimiento, la calidad y conservación de los atractivos turísticos, calidad de los servicios y la satisfacción en general de los servicios recibidos en el destino.

Asimismo, la afluencia de turistas se ha incrementado recientemente por lo antes mencionado, así como por la creciente oferta de servicios turísticos en la zona, el aumento de llegada de vuelos y cruceros internacionales y la belleza escénica y tranquilidad del lugar. No obstante, se debe optimizar las estrategias de desarrollo turístico sostenible para que siga siendo una buena opción para visitar y/o vacacionar, aunado a que de dicha actividad se generen ingresos reales para la población local, además de la captación de divisas, principalmente el dólar americano y canadiense. Dado lo anterior, el presente estudio pretende ofrecer a los tomadores de decisiones información proveniente de los atores clave del lugar y de los turistas, que les ayude al logro de los objetivos marcados en el Programa de Pueblos Mágicos (SECTUR, 2017) donde aluden al fomento del desarrollo sostenible de las localidades que poseen atributos, valores y atractivos, que les brinde exclusividad y prestigio teniendo como referencia las motivaciones y necesidades del viajero. Pero más allá de eso, pretende ser un referente de estudio de caso para localidades con características similares y con altas posibilidades de éxito en el trabajo consensuado.

Los resultados obtenidos de este caso de estudio en Loreto muestran una serie de oportunidades y de ventajas competitivas, entre ellas; su gastronomía, sus sitios históricos y culturales, tiendas artesanales, dulces típicos y la diversidad de flora y fauna (terrestre y marina). Sin embargo, tiene retos por resolver, tal es el caso de la politización del manejo del comité de Pueblos Mágicos ya que muestra una división de opiniones y acciones entre los actores clave que son poco recomendables para cualquier centro turístico, misma que se hace notar en el manejo y directrices que tienen las asociaciones de hoteles del lugar que prácticamente no confluyen en objetivos ni estrategias que deberían de ser comunes.

No obstante de ser calificado como un lugar limpio, el destino y manejo de residuos sólidos y líquidos continúa siendo un problema para la comunidad, lo anterior es un elemento clave para alcanzar la sostenibilidad del destino. Además, la participación marginal o nula de algunos de los tomadores de 
decisiones han conducido a esfuerzos aislados que, si bien están en la línea correcta, hacen que dichos esfuerzos no impacten en el corto tiempo ni de manera contundente.

Sin embargo, la loable labor que realiza la asociación civil Eco Alianza es reconocida y aplaudida por todos los actores del medio turístico de Loreto, pero el apoyo que se da a este trabajo es sumamente desigual y no siempre se hace tangible quedando, en algunos casos, en el discurso. La sostenibilidad con su trasfondo cultural de valores y costumbres no ha permeado sensiblemente a todos los actores que simplemente lo ven como algo conveniente o que les brinda una buena imagen.

Por otro lado, las autoridades federales, principales responsables del manejo del PNBL, han dejado mucho por hacer debido al poco o nulo apoyo financiero que se destina para tal fin. Lo anterior puede tener consecuencias como depredación y manejo deficiente de los recursos del Parque, lo cual puede traducirse en efectos negativos en el mediano y largo plazo, esto por supuesto también tendría su efecto desfavorable en el destino turístico ya que es uno de sus principales atractivos.

En Loreto, el turismo ha sido una actividad económica que ha detonado la creación de empleos y alguna mejora en la infraestructura de servicios de la localidad, por lo anterior, los entrevistados comentan que esto también se ha reflejado en un encarecimiento de la vida y otros procesos de transculturización y aculturación inherentes al turismo. Lo anterior pone en relieve la necesidad de hacer políticas transversales para el desarrollo del destino turístico con el objeto de transferir este bienestar de una forma más equitativa a todos los involucrados en la actividad turística.

La calificación de los componentes turísticos a partir de la percepción de los turistas de Loreto es positiva, no obstante, es recomendable que exista una planificación, no solo para la preservación de su patrimonio natural y cultural, sino para el incremento del bienestar de su población. Esto debe lograrse con una extensiva y dinámica participación de todos los involucrados directa o indirectamente en el turismo buscando que Loreto se convierta en referente de calidad turística sostenible.

Finalmente, se recomienda apoyar empresas con enfoque sostenible, acordar estrategias con los tres niveles de gobierno y con la sociedad para la conservación y mantenimiento de áreas naturales y parques, restaurar sitios naturales para asegurar la presencia de flora y fauna, contar con campañas de limpieza de playas, inspección y vigilancia de playas y zona marina, contar con depósitos de basura con clasificación de residuos, estrategias de limpieza de calles y sitios públicos en todo el pueblo, no solo en sitios turísticos. Además, promover acciones de planeación estratégica del turismo y el desarrollo sustentable del destino con el involucramiento de la sociedad en la toma de decisiones, promover mejoras en la imagen urbana que resalte los atractivos turísticos y productos naturales y culturales. También, se recomiendan líneas de investigación futuras tales como monitoreo constante de indicadores del uso sostenible de los recursos naturales y estudios de capacidad de carga turística en el PNBL, lo que permitirá a los tomadores de decisiones implementar estrategias innovadoras que permitan anticiparse a la creciente demanda del TS. En el caso de la localidad de San Javier se recomienda evaluar a capacidad de carga del sitio, tener un ingreso controlado de las visitas y contar con un plan estratégico para el fomento del TS.

\section{Bibliografía}

Bezaury-Creel, J., D. Gutiérrez Carbonell 2009. Áreas naturales protegidas y desarrollo social en México, en Capital natural de México, vol. II: Estado de conservación y tendencias de cambio. Conabio, México, pp. 385-431.

Calero Vinelo, A. 1978. Técnicas de Muestreo. La Habana, Cuba: Editorial. Pueblo y Educación.

Cardoso Jiménez, C. 2006. Turismo Sostenible: una revisión conceptual aplicada. En El Periplo Sustentable mayo 2006. Disponible en: http://www.redalyc.org/articulo.oa?id=193420679001, [29 de abril de 2019]

Cruz, P., Cruz, G., Juárez, J. y Urciaga J. 2016. "Divergencias de competitividad en destinos turísticos de Baja California Sur". Global Conference on Business and Finance Proceedings, Vol. 4, No. 8, pp. 95-104.

DOF (Diario Oficial de la Federación de México) 2018. Ley General del Equilibrio Ecológico y la Protección al Ambiente. Diario Oficial de la Federación el 28 de enero de 1988 texto vigente última reforma publicada DOF 05-06-2018. Ciudad de México, México: Gobierno de la República Mexicana

Eisenhardt, K. y Graebner, M. 2007. Theory building from cases: Opportunities and challenges. Academy of Management Journal, (50), 25-32.

Gob. BCS (Gobierno de Baja California Sur) 2019. Instituto sudcaliforniano de cultura, recintos de Loreto, Recuperado de https://culturabcs.gob.mx/recintos-bcs/loreto

Gobierno del estado de Baja California Sur. 2018. Tercer informe de gobierno. Anexo estadístico y gráfico. Recuperado de http://www.bcs.gob.mx/docs/2do-informe/Anexo-Grafico-y-Estadistico-2do-Informe-de-Gobierno.pdf 
Hancock D.R. y Algozzine B. 2006. Doing Case Study Research, A Practical Guide for Beginning Researchers. Teachers College, New York: Columbia University.

Hernández Sampieri, R., Fernández Collado, C., y Baptista Lucio, P. 2014. Metodología de la Investigación. México: Mac Graw Hill.

Hoyos Castillo, G. y Hernández Lara, O. 2008. Localidades con recursos turísticos y el programa pueblos mágicos en medio del proceso de la nueva ruralidad. los casos de Tepotzotlán y Valle de Bravo en el Estado de México. Quivera, 10(2), 111-130.

Ibáñez Pérez, R. y Olmos-Martínez, E. 2015. Percepción comunitaria y potencial ecoturístico en una unidad de manejo ambiental. En: A. Mendieta Ramírez (coord.). ¿Legitimidad o reconocimiento? Las investigadoras del SNI. Retos y propuestas. (pp. 611-617). Puebla, México: Benemérita Universidad Autónoma de Puebla y Ediciones La Biblioteca, S.A.

Ibarra Michel, J. P. y Velarde Valdés, M. 2016. El Programa Pueblos Mágicos y la sustentabilidad turística; el caso de Cosalá y los eventos "Cosaltazo" y "Cosalazo". El Periplo sustentable, (31), Recuperado de https://rperiplo.uaemex.mx/article/view/4885

INEGI (Instituto Nacional de Estadística y Geografía) 2017. Anuario estadístico y geográfico de Baja California Sur 2017. Instituto Nacional de Estadística y Geografía. México.

Leiva, V. y Rivas, H. 1997. Turismo y gestión municipal. Asociación Chilena de Municipalidades. Santiago. Chile

Martín-Crespo, M. C. y Salamanca, A. B. (2007). El Muestreo en la investigación cualitativa. Nure Investigación, 4 (27), 3-7.

Masri, S. y Robles, L. M. 1997. La industria turística: hacia la sustentabilidad. México: Diana.

Naciones Unidas 1987. Informe de la Comisión Mundial sobre el Medio Ambiente y el Desarrollo "Nuestro futuro común".

OMT (Organización Mundial de Turismo) 2005. Indicadores de desarrollo sostenible para los destinos turísticos. Guía práctica. OMT. Madrid

OMT (Organización Mundial de Turismo) 2006. Por un turismo más sostenible - Guía para responsables políticos. PNUMA y OMT.

Rodríguez Peñuelas, M. A. 2010. Métodos de investigación. 1ra. Edición, México. Ed. Universidad Autónoma de Sinaloa.

Salinas Chávez, E., Navarro Jurado, Enrique, Echarri Chávez, M. y La O Osorio, J. A. 2008. Metodologías para la evolución de la sustentabilidad territorial: el uso de indicadores en destinos turísticos de cuba. Boletín de la R.S.G. CXLIV. 77-102.

Salinas, E. y J. A. La O 2006. Turismo y sustentabilidad: de la teoría a la práctica en Cuba. Cuadernos de Turismo (17), 203-223.

SECTUR (Secretaría de Turismo de México) 2014. Guía de incorporación y permanencia Pueblos Mágicos.

SECTUR-SEMARNAT (Secretaría de Turismo-Secretaría del Medio Ambiente y Recursos Naturales de México). (2013). Agenda 21 para el Turismo Mexicano. Recuperado de http://www.sectur.gob.mx/ work/models/sectur/Resource/5975/1/images/Agenda21.pdf

SEMARNAP-CONANP (Secretaría del Medio Ambiente, Recursos Naturales y Pesca-Comisión Nacional de Áreas Naturales Protegidas de México) 2000. Programa de manejo del Parque nacional Bahía de Loreto. Ciudad de México, México: SEMARNAT-CONANP.

Soares, Moraes, D. 2003. Género y ambiente: una aproximación a las relaciones socioambientales en dos comunidades de la llanura costera del municipio de Loreto, Baja California Sur, México. La ventana, (17), 140-187.

UNWTO (World Tourism Organization) 2018. Annual Report 2017, UNWTO, Madrid, DOI: https://doi. org/10.18111/9789284419807.

Verdugo Partida, M.D. 2017. Evaluación de la vulnerabilidad como elemento base para el manejo de un ANP: Parque Nacional Bahía de Loreto, México. Tesis para obtener el grado de Maestro en Ciencias Marinas y Costeras con orientación en manejo sustentable, Universidad Autónoma de Baja California Sur.

Recibido:

$16 / 08 / 2019$

Reenviado:

$27 / 11 / 2019$

Aceptado:

$14 / 01 / 2020$

Sometido a evaluación por pares anónimos 